\title{
A Robust Multifunctional Sandwich Panel Design with Trabecular Structures by the Use of Additive Manufacturing Technology for a New De-Icing System
}

\author{
Carlo Giovanni Ferro ${ }^{1, *}$, Sara Varetti ${ }^{2,3}$, Fabio Vitti ${ }^{1}$, Paolo Maggiore ${ }^{1}$, Mariangela Lombardi ${ }^{3}$, \\ Sara Biamino ${ }^{3}$, Diego Manfredi ${ }^{4}$ and Flaviana Calignano ${ }^{4}$ \\ 1 Department of Mechanical Engineering and Aerospace (DIMEAS), Politecnico di Torino, \\ Corso Duca Degli Abruzzi 24, 10129 Turin, Italy; fabio.vitti.sc@gmail.com (F.V.); paolo.maggiore@polito.it (P.M.) \\ 2 3D-New Technologies (3D-NT), via Livorno 60, 10144 Turin, Italy; sara.varetti@polito.it \\ 3 Department of Applied Science and Technology (DISAT), Politecnico di Torino, \\ Corso Duca Degli Abruzzi 24, 10129 Turin, Italy; mariangela.lombardi@polito.it (M.L.); \\ sara.biamino@polito.it (S.B.) \\ 4 Center for Sustainable Future Technologies CSFT@Polito, Istituto Italiano di Tecnologia (IIT), \\ Corso Trento 21, 10129 Turin, Italy; Diego.Manfredi@iit.it (D.M.); Flaviana.Calignano@iit.it (F.C.) \\ * Correspondence: carlo.ferro@polito.it; Tel.: +39-11-090-6858
}

Academic Editor: Manoj Gupta

Received: 29 January 2017; Accepted: 7 June 2017; Published: 15 June 2017

\begin{abstract}
Anti-ice systems assure a vital on-board function in most aircraft: ice prevention or de-icing is mandatory for all aerodynamic surfaces to preserve their performance, and for all the movable surfaces to allow the proper control of the plane. In this work, a novel multi-functional panel concept which integrates anti-icing directly inside the primary structure is presented. In fact, constructing the core of the sandwich with trabecular non-stochastic cells allows the presence of a heat exchanger directly inside the structure with a savings in weight and an improvement in thermal efficiency. This solution can be realized easily in a single-piece component using Additive Manufacturing (AM) technology without the need for joints, gluing, or welding. The objective of this study is to preliminarily investigate the mechanical properties of the core constructed with Selective Laser Melting (SLM); through the Design of Experiment (DOE), different design parameters were varied to understand how they affect the compression behaviour.
\end{abstract}

Keywords: Additive Manufacturing (AM); Selective Laser Melting (SLM); advanced structures; anti-ice systems; lattice structures; Design of Experiment

\section{Introduction}

Icing on aircraft is a concrete and severe problem and has led to direct or indirect hazards and fatal crashes during recent years [1,2]. The phenomenon is caused by supercooled droplets of water normally present in clouds that strike the leading edges of aircraft and freeze on impact [3].

The ice type formed on aircraft parts depends on the weather and the temperature of the contact surface [4-8]. Among the most common ice types are clear ice, formed from big water droplets, most tenacious and heavy to remove and SLD (Supercooled Large Droplets) ice, similar to clear ice but more extended, and can cause severe damage as in the crash of the American Eagle Flight 4184 [9]. Another common ice type is rime ice, which is formed by smaller diameter droplets and is easy to remove due to its fragility. Finally, mixed ice, with intermediate characteristics, is also common.

One of the main risks due to icing during flight is aerodynamic hazard, beacause the formation of ice may cause the modification of the airfoil profile and so increases the drag united with the decrease in lift. Another possible risk factor is represented by structural systems hazards, wich are related to the 
additional weight that unbalances structural parts affected by ice formation (rotor propellers, antennas, main rotor of helicopters, etc.). Systems hazards are a further source of risk, and occur when ice causes the lock of surfaces that may lead to the loss of control of the flight.

Anti-icing systems need to protect the exposed parts from ice and rain, namely wing leading edges, horizontal and vertical stabilizers, engine nacelle leading edges (engine fans have to face the FOD (Foreign Object Debris) problem), propellers, air data probe (Pitot), windows of the flight deck, antennas and water and waste systems. The most frequently used anti-icing systems are thermal; in fact, the use of heating fluids or electrical resistances for maintaining the adequate temperature on the outer surface of the wing is common to many patented systems. According to civil regulation [10], the system must withstand ice formation in an atmosphere at $-9.4{ }^{\circ} \mathrm{C}$, with a LWC (Liquid Water Content) of $0.5 \mathrm{~g} / \mathrm{m}^{3}$ and a droplet mean volumetric diameter (DMVD) of 20 microns. A wide range of patents describe the use of hot air bled from the compressor of the turbo-engine as heat carrier. The hot air enters structures necessary for the transport of heat on the outer surface. These structures may be inflatable elements affixed on the leading edge insufflated with hot air [11], or porous leading edges through which the anti-ice fluid flows [12]. Other structures are pipes that carry hot air up to the inner surface of the panel [13], leading edges with internal pipes that favour the forced air path next to the outer sheet [14], and finally a series of systems which require the use of ducts and interstices used as de-icing installations [15].

In this work, a new patented [16] system for the de-icing and the anti-icing of airplanes is presented, together with its method of fabrication. The novelty of this system is the integration of hot air passageways and feeding tubes in a single-piece structural panel of the wing leading edge, without the necessity of welding or other kinds of joining. This novel system allows an important savings in the mass of the primary structure, and an improvement of the thermal efficiency of the de-icing function. The system is a sandwich panel composed by core, outer, and inner skin. The core is produced with a non-stochastic lattice structure, while the external skin is the aerodynamic surface, and the internal skin integrates the feeding tubes that collect the hot air bled from the compressor.

The use of sandwich panels with trabecular structure as a core ensures a high specific surface area that optimizes heat exchange. The panel must be manufactured in a single material and in one piece. The realization of structures of this type, with a controlled porosity, reduced dimensions of the details, and articulated geometry, is very difficult to achieve with traditional foundry and molding techniques. These needs may instead be exhaustively fulfilled by additive manufacturing technologies, in particular selective laser melting (SLM), a laser powder bed fusion (LPBF) process that allows the manufacturing of metal components through selective melting of powders, layer by layer $[17,18]$. Fusion occurs only in the areas necessary for the realization of the component according to the information obtained by the stereo lithography (STL) digital format of the 3D model. The energy required to melt the powder is supplied by a laser beam $[19,20]$ in inert atmosphere $\left(N_{2}\right.$, Ar). Additive manufacturing is the only technology which allows the realization of a single-piece panel in a single material and with a complex geometry core.

In the literature, there are several works that describe the feasibility and the behaviour of periodic lattice structures using different materials and additive technologies such as SLM and electron beam melting (EBM). The studied geometries range from BCC (body-centered cubic) and FCC (face-centered cubic), with their variants, to more complex cells such as gyroid and diamond [21,22]. Many papers report the results of FE models and mechanical tests, especially compression tests, on samples with lattice structures, through the study of the fracture mechanics [23-30].

SLM technology was used in the study of trabecular structures of 316L stainless steel [31-37] and aluminum alloys such as AlSi10Mg [21,22,38-40]. Al alloys are particularly suited for the application described in the present paper, as $\mathrm{Al}$ alloys show excellent thermal conductivity and excellent corrosion resistance. The purpose of the investigations is to choose the best core structure that constitutes the sandwich panel, so different types of specimens were produced with varying strut thickness, cell type, 
and cell size. An analysis of their compressive behaviour was conducted to assess which of these factors is most influential on mechanical properties.

\section{Material and Methods}

In order to evaluate the properties of the trabecular core, mechanical tests were carried out on different cell types. Taking as input both technical constraint and thermal-mechanical request, a $2^{3}$ Full Factorial DOE (Design Of Experiment) was imposed. Two promising cell types were chosen to evaluate the compressive behaviour varying strut size $(1 \mathrm{~mm}$ and $1.2 \mathrm{~mm})$ and cell size $(4 \mathrm{~mm}$ and $5 \mathrm{~mm})$. This approach was applied to produce lattice samples and to experimentally test the mechanical properties. In Figure 1, two of the 3D models of the specimens produced are presented. The geometries of the models correspond to a body-centered cubic (bcc) structure and to a body-centered cubic with vertical struts along the $Z$ axis (bcc-z). Eight kinds of specimens were realized, with two samples for each type. Table 1 lists the specimens with the respective characteristics (cell type, cell size, and strut size).

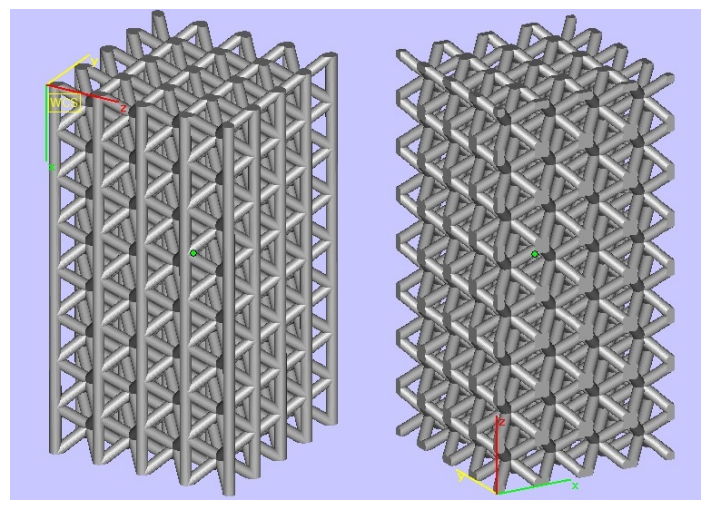

Figure 1. 3D models of trabecular specimens with bcc-z and bcc cell type.

Table 1. List of specimens produced and their characteristics.

\begin{tabular}{cccc}
\hline Samples Name & Cell Size (mm) & Strut Size (mm) & Cell Type \\
\hline $4-1-\mathrm{bcc}-\mathrm{z}$ & 4 & 1 & $\mathrm{bcc-z}^{*}$ \\
$4-1.2-\mathrm{bcc}-\mathrm{z}$ & 4 & 1.2 & $\mathrm{bcc}^{*}$ \\
$5-1-\mathrm{bcc-z}$ & 5 & 1 & $\mathrm{bcc}^{*}$ \\
$5-1.2-\mathrm{bcc}-\mathrm{z}$ & 5 & 1.2 & $\mathrm{bcc}^{*}$ \\
$4-1-\mathrm{bcc}$ & 4 & 1 & $\mathrm{bcc}^{* *}$ \\
$4-1.2-\mathrm{bcc}$ & 4 & 1.2 & $\mathrm{bcc}$ \\
$5-1-\mathrm{bcc}$ & 5 & 1 & $\mathrm{bcc}^{* *}$ \\
$5-1.2-\mathrm{bcc}$ & 5 & 1.2 & $\mathrm{bcc}^{* *}$ \\
\hline
\end{tabular}

* Body-centered cubic with vertical struts along $\mathrm{Z}$ axis; ${ }^{* *}$ Body-centered cubic.

All samples were made with the EOS machine M270 Dual Mode Version with SLM technology. They grew in height, with a square base resting on the plate. The thickness of the powder bed layer was $30 \mu \mathrm{m}$. The powder used was AlSi10Mg, a typical casting alloy that offers good strength, hardness, and is also used for parts subjected to high loads. AlSi10Mg is suitable for applications that require both good thermal properties and low weight. The dimensions of the specimens constructed were $20 \mathrm{~mm}$ of base size and $40 \mathrm{~mm}$ of height. All compression tests were performed with a Zwick Roell machine: the samples were compressed along the $Z$ axis, with the $X Y$ faces in contact with the plates. A preload of $1 \mathrm{kN}$ was imposed, and then a load cell of $50 \mathrm{kN}$ was applied by setting a constant displacement of $1 \mathrm{~mm} / \mathrm{min}$.

From mechanical characteristics obtained for each specimen, the influence of all factors on the performance can be estimated. The main effect was calculated for the specific elastic modulus $(E / \rho)$, specific maximum stress $\left(\sigma_{\max } / \rho\right)$, and specific stress corresponding to a permanent deformation of 
$0.2 \%\left(\sigma_{0.2} / \rho\right)$. The plots, realized with Minitab, show the effect of strut size, cell size, and cell type on specific mechanical properties of the specimens. The influence of each factor on the final parameter was obtained from the slope of the line in the graph (in modulus): the greater the slope, the greater the influence. The slope is calculated as $\Delta Y / \Delta X$, where $\Delta Y$ is the difference between the average values of the property (example: $(E / \rho)_{1.2, \text { average }}-(E / \rho)_{1, \text { average }}=\Delta Y$ ), and $\Delta X$ is assumed unitary in order to compare the slopes. The same procedure was used for all data and all factors.

Further analysis of the effects of each factor was conducted with Pareto charts. The Pareto principle says that most of the effect is due to a small number of causes: this means that $80 \%$ of the effects are achieved by using $20 \%$ of the factors. The use of this graph allows the evaluation of not only the influence of factors, but also the influence of their interactions. In fact, the effect of factors and interactions is not the same; some have greater influence and others minor.

\section{Results}

The obtained results led to qualitative inferences useful for the design of new experiments on the cellular core. The core is the most important structural part, and its compressive strength, which is the subject of the first part of characterization, is fundamental. Figure 2 illustrates the entire panel with the internal lattices, the external skins, and the feeding tubes integrated into a single component. In the structure there are no rivets and joinings which are present in the traditional thermal systems (e.g., that of Piaggio P180 shown in the Figure 3), and so unpleasant phenomena like cracks or damages can be overcome.

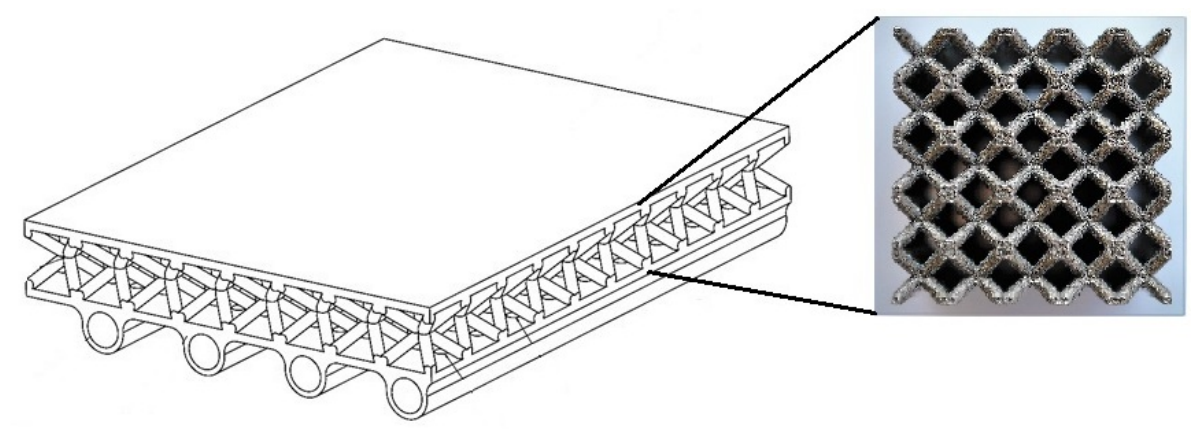

Figure 2. Section of the panel.
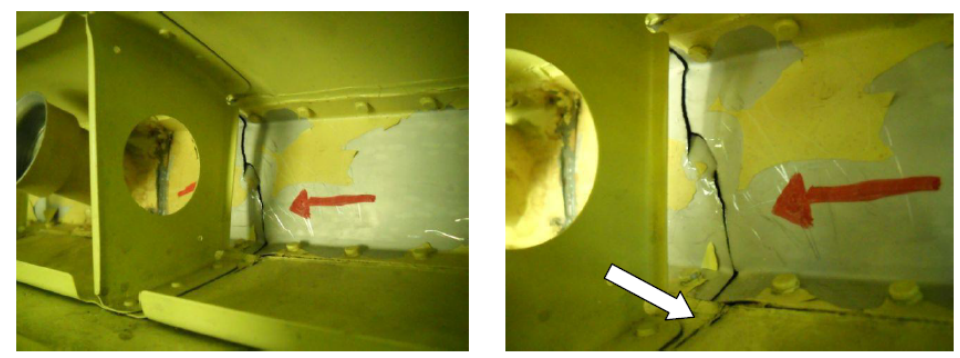

Figure 3. Internal structure of Piaggio thermal anti-icing system, with cracks evidenced by red arrows, courtesy of [41].

In Table 2, pure and specific mechanical properties are reported. The specific values were obtained by dividing $\mathrm{E}, \sigma_{\max }, \sigma_{0.2}$ for the density of each specimen. The best elastic modulus and the greatest stresses $\left(\sigma_{\max }\right.$ and $\left.\sigma_{0.2}\right)$ were obtained for the specimen with $4 \mathrm{~mm}$ cell size, $1.2 \mathrm{~mm}$ strut size, and with bcc-z cell geometry. The DOE approach allows an easy evaluation of the single effect of each variable, in order to identify the most influential factor. 
Table 2. Mechanical properties of the specimens tested.

\begin{tabular}{|c|c|c|c|c|c|c|}
\hline Samples & $\begin{array}{c}\mathrm{E} \\
(\mathrm{MPa})\end{array}$ & $\begin{array}{c}\sigma_{\max } \\
\mathbf{( M P a )}\end{array}$ & $\begin{array}{c}\sigma_{0.2} \\
(\mathrm{MPa})\end{array}$ & $\begin{array}{c}E / \rho \\
\left(\mathrm{MPa} \cdot \mathrm{dm}^{3} / \mathrm{kg}\right)\end{array}$ & $\begin{array}{c}\sigma_{\max } / \rho \\
\left(\mathrm{MPa} \cdot \mathrm{dm}^{3} / \mathrm{kg}\right)\end{array}$ & $\begin{array}{c}\sigma_{0.2} / \rho \\
\left(\mathrm{MPa} \cdot \mathrm{dm}^{3} / \mathrm{kg}\right)\end{array}$ \\
\hline 4-1-bcc-z & 1054 & 29 & 20 & 1576 & 43 & 30 \\
\hline 4-1.2-bcc-z & 1465 & 54 & 37 & 1587 & 59 & 40 \\
\hline 5-1-bcc-z & 565 & 15 & 13 & 1263 & 33 & 28 \\
\hline 5-1.2-bcc-z & 933 & 29 & 22 & 1463 & 45 & 35 \\
\hline 4-1-bcc & 216 & 11 & 10 & 357 & 18 & 16 \\
\hline 4-1.2-bcc & 717 & 24 & 18 & 852 & 29 & 22 \\
\hline 5-1-bcc & 63 & 4 & 4 & 154 & 11 & 11 \\
\hline 5-1.2-bcc & 253 & 10 & 9 & 434 & 17 & 15 \\
\hline
\end{tabular}

The main effect charts in Figure 4a,c,e show the effect of strut size, cell size, and cell type on $E / \rho$, $\sigma_{\max } / \rho$, and $\sigma_{0.2} / \rho$ for the tested specimens. The slopes of the lines indicate that the increase in the strut size has a positive effect on the mechanical behaviour, leading to a more dense and stronger trabecular structure. For the same reason, the increase of the cell size leads to a reduction in the density of the foam, with a decrease in elastic modulus, in $\sigma_{m a x}$, and in $\sigma_{0.2}$. Finally, a positive result can be noticed looking at the effect of cell type: the presence of vertical struts leads to a stiffer foam. Comparing the slopes, it appears that the factor that most influences the specific properties is the cell type. Passing from a bcc cell type to a bcc-z cell type, an increase in $E / \rho, \sigma_{\max } / \rho$, and $\sigma_{0.2} / \rho$ was noticed. This increase is greater than that obtained, for example, by varying the strut size from 1 to $1.2 \mathrm{~mm}$. The influence of cell size and of strut size, instead, is similar. The slopes reported for $E / \rho, \sigma_{\max } / \rho$, and $\sigma_{0.2} / \rho$ follow the same behaviour: a stiffer and more dense structure leads to an improvement of the mechanical properties. In all cases, the factor that most influences the parameters is the cell type.

The dot-plots reported in Figure $4 \mathrm{~b}, \mathrm{~d}, \mathrm{f}$ show a low dispersion of the data for $E / \rho, \sigma_{\max } / \rho$, and $\sigma_{0.2} / \rho$, with the same cell shape, while a high dispersion is presented for the other two factors. This is also due to the decisive role of the cell shape on mechanical behavior, compared to the effect of strut size and cell size.

Further analysis of the specimens was conducted, plotting the Pareto charts, reported in Figure 5. Regarding the specific elastic modulus, the greatest influential factor is the cell type, and it is also the only one above the significance value. Immediately after single factors, there is a second-order interaction between cell type and strut size, and then there are the third-order interaction and all the other second-order interactions. The Pareto charts for $\sigma_{\max } / \rho$ and $\sigma_{0.2} / \rho$ (Figure 5) show that the greatest influence on the output is given by the cell type, but different values are reported: for $\sigma_{\max } / \rho$, all the single factors seem to be significant, while for $\sigma_{0.2} / \rho$, only the cell type seems to be. Moreover, the second factor that influences the specific stresses is the strut size, but not the cell size, as seen before for the specific elastic modulus. 


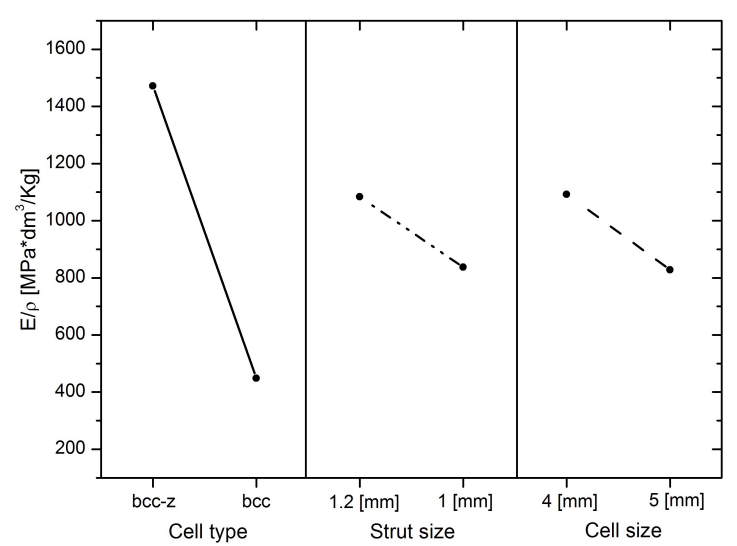

(a) Main effect plots for $E / \rho$.

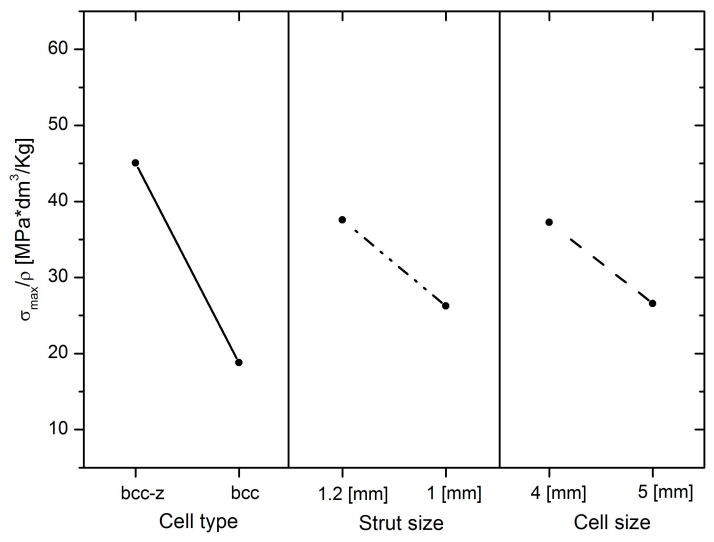

(c) Main effect plots for $\sigma_{\max } / \rho$.

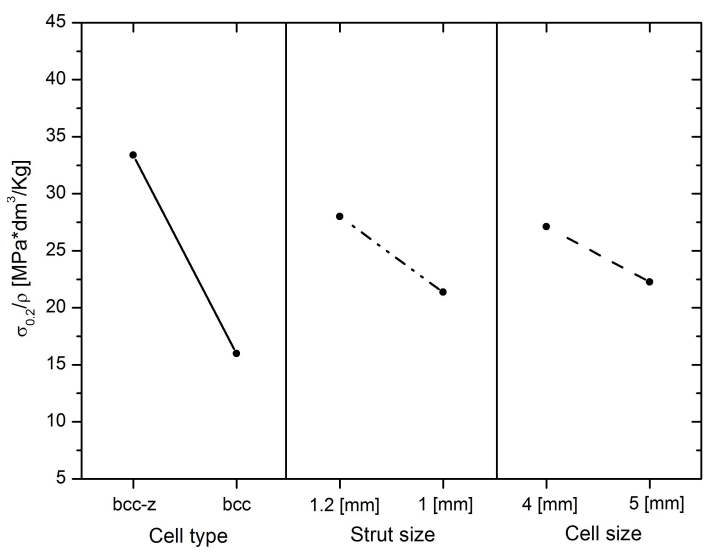

(e) Main effect plots for $\sigma_{0.2} / \rho$.

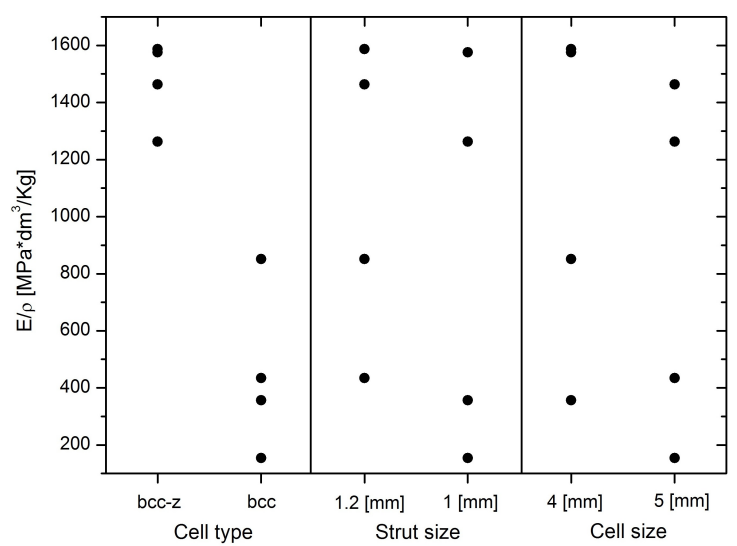

(b) Dot plots for $E / \rho$.

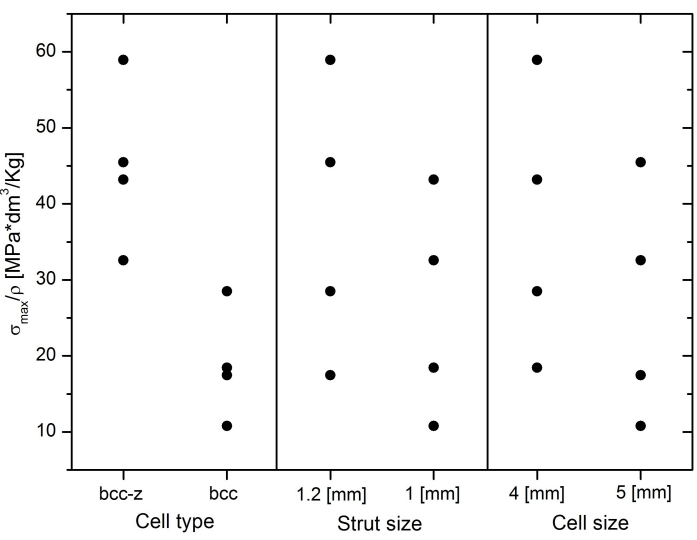

(d) Dot plots for $\sigma_{\max } / \rho$.

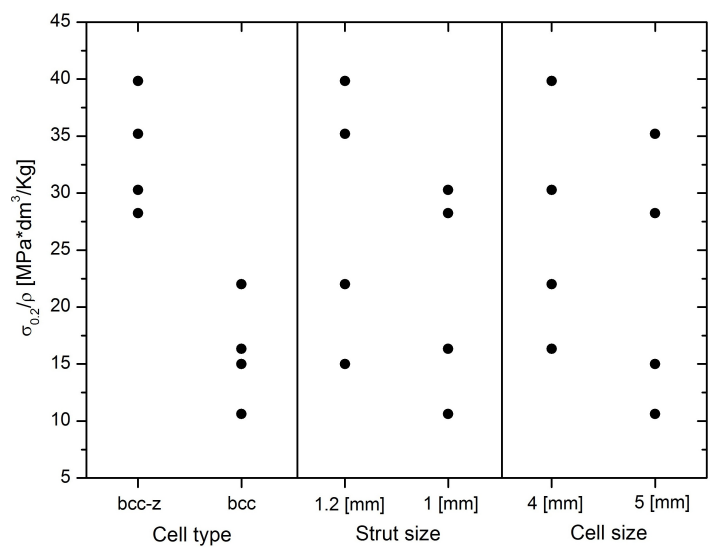

(f) Dot plots for $\sigma_{0.2} / \rho$.

Figure 4. Main effect plots and dot-plots for the specific elastic modulus, specific maximum stress, and specific stress for $0.2 \%$ of deformation. 

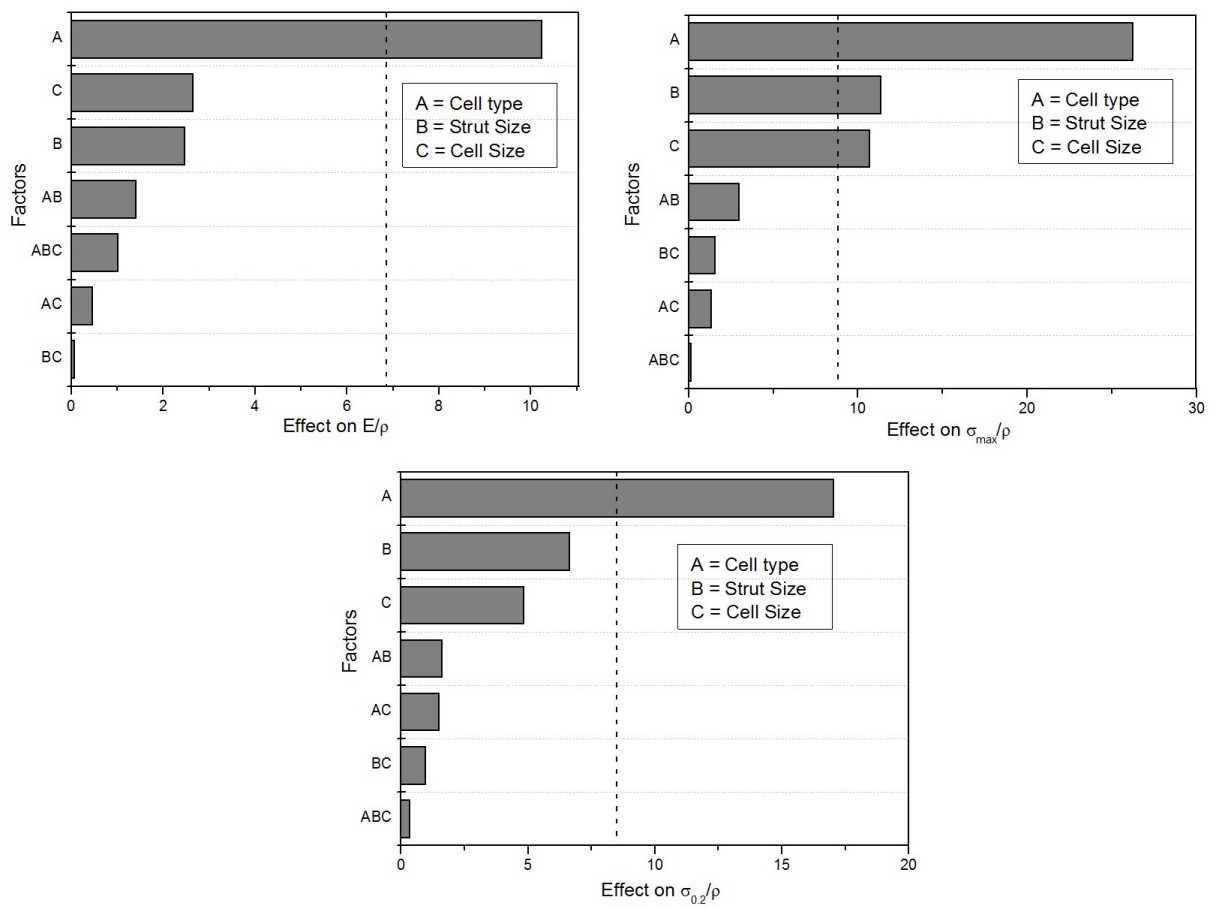

Figure 5. Pareto charts for $E / \rho, \sigma_{0.2} / \rho$, and $\sigma_{\max } / \rho$.

\section{Discussion}

From the results reported in the previous section, few assumptions can be summarized, providing general rules. The first consideration is that the presence of vertical struts, although they have a buckling failure, leads to the best mechanical performance, both in terms of specific elastic modulus and in terms of strengths. The second observation is closely linked to the first one: the most important design variable is the cell type and so the struts orientation, with a magnitude superior to the other two factors. The third point is that a more dense structure (thicker struts and smaller cells) always gives better results. This fact is pretty understandable, since these changes imply an increase in the effective resistant area and a rise in the global amount of density. With these considerations, it is possible to correctly design a core for the sandwich panel, allowing it to sustain the normal pressure of the aerodynamic load during flight, reducing masses, and improving mechanical performances.

\section{Conclusions and Further Improvements}

In this paper, the idea of a multi-functional panel is described together with an experimental evaluation of some design parameters by compression tests. The additive manufacturing technology is tested for the production of non-stochastic cells, and it appears suitable to the purpose. The experiments aimed at the characterization of the panels, starting with the present work, will continue with the construction of other specimens and with bending, tension, and impact tests. Moreover, future works will include a multidisciplinary optimization of the trabeculae, considering thermal phenomena (with lumped parameters models and CFD (Computational Fluid Dynamics) analysis) and mechanical behaviour of the panel. At the end, a de-icing test will be carried out by subjecting the sandwich panel with a trabecular core to humidity, temperature, and pressure conditions identical to those in flight condition. The experiments will allow the de-icing effectiveness to be analysed.

Author Contributions: Carlo Giovanni Ferro, Sara Varetti and Fabio Vitti conceived and designed the experiments under the supervision of Paolo Maggiore, Mariangela Lombardi and Sara Biamino. Sara Varetti performed the experiments and analyzed the data with Carlo Giovanni Ferro. Flaviana Calignano and Diego Manfredi contributed with materials and specimens. All authors discussed and analyzed the results, contributed to writing and approved the final manuscript. 
Conflicts of Interest: The authors declare no conflict of interest.

\section{References and Note}

1. Bureau d'Enquêtes et d'Analyses pour la sécurité de l'aviation civile (BEA). Final Report on the Accident on 1 June 2009 to the Airbus A330-203 Registered F-GZCP Operated by Air France Flight AF 447 Rio de Janeiro-Paris. BEA 2012, 10. Available online: https://www.bea.aero/en/investigation-reports/ notified-events/detail/event/accident-of-an-airbus-a330-203-registered-f-gzcp-and-operated-by-airfrance-crashed-into-the-atlanti/ (accessed on 14 June 2017).

2. Transportation Safety Board of Canada (TSBC). Final Report on the Transportation Safety Board of Canada's Investigation into the Accident Involving an Air Canada Flight 646 Regional Jet at Fredericton, New Brunswick, on the Night of 16 December 1997. TSBC 1999, 10. Available online: http:/ /www.tsb.gc.ca/ ENG/medias-media/communiques/aviation/1999/comm_a97h0011.asp (accessed on 14 June 2017).

3. Federal Aviation Administration (FAA). In Aircraft Icing Handbook; FAA Technical Center: Atlantic City, NJ, USA, 1991.

4. Politovich, M.K. Aviation Meteorology: Aircraft Icing. In Encyclopedia of Atmospheric Sciences; National Center for Atmospheric Research, Boulder: Boulder, CO, USA, 2015; pp. 160-165.

5. Cao, Y.; Wu, Z.; Su, Y.; Xu, Z. Aircraft flight characteristics in icing conditions. Progress Aerosp. Sci. 2015, 74, 62-80.

6. Li, X.; Bai, J.; Hua, J.; Wang, K.; Zhang, Y. A spongy icing model for aircraft icing. Chin. J. Aeronaut. 2014, 27, $40-51$.

7. Srensen, K.L.; Blanke, M.; Johansen, T.A. Diagnosis of Wing Icing Through Lift and Drag Coefficient Change Detection for Small Unmanned Aircraft. IFAC-PapersOnLine 2015, 48, 541-546.

8. Parent, O.; Ilinca, A. Anti-icing and de-icing techniques for wind turbines: Critical review. Cold Reg. Sci. Technol. 2011, 65, 88-96.

9. National Transport and Safety Authority (NTSA). National Transportation Safety Board (NTSB) Aircraft Accident Report, Monday 31 October 1994. Transportation Safety Board of Canada (TSBC) 1996, 10. Available online: https://www.ntsb.gov/investigations/AccidentReports/Pages/AAR9601.aspx (accessed on 14 June 2017).

10. Federal Aviation Administration (FAA). MIL-A-9482 Anti-Icing Equipment for Aircraft, Heated Surface Type, General Specification; FAA Technical Center: Atlantic City, NJ, USA, 1981.

11. Goodman, J. Means for Preventing Ice Formation on Aircraft Wings. U.S. Patent 2,328,079, 31 August 1943.

12. Garrison, M.E. Airplane Wing Deicing Means. U.S. Patent 2,390,093, 4 December 1945.

13. Schmidt, H.F. Airplane Anti-Icing System. U.S. Patent 2,447,095, 17 August 1948.

14. Ayers, M.; Barrick, R.E. Airplane Wing Leading Edge Costruction. U.S. Patent 2,470,128, 17 May 1949.

15. Dodson, P.A.; Smith, L.H. Deicing Wing Costruction. U.S. Patent 2,478,878, 9 August 1949.

16. Giovanni, F.C.; Varetti, S.; Vitti, F.; Maggiore, P. An Aircraft Equipped with Astructurally Integrated De-Icing System. IT102016000098196, 2016.

17. Ford, S.; Despeisse, M. Additive manufacturing and sustainability: An exploratory study of the advantages and challenges. J. Clean. Prod. 2016, 137, 1573-1587.

18. Moylan, S.; Whitenton, E.; Lane, B.; Slotwinski, J. Infrared Thermography for Laser-Based Powder Bed Fusion Additive Manufacturing Processes. In Proceedings of the 40th Annual Review of Progress in Quantitative Nondestructive Evaluation, Baltimore, MD, USA, 21-26 July 2013; pp. 1191-1196.

19. Kempen, K.; Thijs, J.; Van Humbeeck, J.; Kruth, J.-P. Mechanical properties of AlSi10Mg produced by Selective Laser Melting. Phys. Proced. 2012, 39, 439-446.

20. Wong, K.V.; Hernandez, A. A Review of Additive Manufacturing. ISRN Mech. Eng. 2012, 2012, 208760, doi:10.5402/2012/208760.

21. Yan, C.; Hao, L.; Hussein, A.; Young, P.; Huang, J.; Zhu, W. Microstructure and mechanical properties of aluminium alloy cellular lattice structures manufactured by direct metal laser sintering. Mater. Sci. Eng. A 2015, 628, 238-246.

22. Yan, C.; Hao, L.; Hussein, A.; Bubb, S.L.; Young, P.; Raymont, D. Evaluation of light weight AlSi10Mg periodic cellular lattice structures fabricated via direct metal laser sintering. J. Mater. Process. Technol. 2014, $214,856-864$. 
23. Cansizoglu, O.; Harrysson, O.; Cormier, D.; West, H.; Mahale, T. Properties of Ti6Al4V non stochastic lattice structures fabricated via electron beam melting. Mater. Sci. Eng. A 2008, 492, 468-474.

24. Murr, L.E.; Gaytan, S.M.; Medina, F.; Martinez, E.; Martinez, J.L.; Hernandez, D.H.; Machado, B.I.; Ramirez, D.A.; Wicker, R.B. Characterization of Ti6Al4V open cellular foams fabricated by additive manufacturing using electron beam melting. Mater. Sci. Eng. A 2010, 527, 1861-1868.

25. Zhao, S.; Li, S.J.; Hou, W.T.; Hao, Y.L.; Yang, R.; Misra, R.D.K. The influence of cell morphology on the compressive fatigue behavior of Ti6Al4V meshes fabricated by electron beam melting. J. Mech. Behav. Biomed. Mater. 2016, 59, 251-264.

26. Li, S.J.; Murr, L.E.; Cheng, X.Y.; Zhang, Z.B.; Hao, Y.L.; Yang, R.; Medina, F.; Wicker, R.B. Compression fatigue behavior of Ti-6Al-4V mesh arrays fabricated by electron beam melting. Acta Mater. 2012, 60, 793-802.

27. Gorny, B.; Niendorf, T.; Lackmann, J.; Thoene, M.; Troester, T.; Maier, H.J. In situ characterization of the deformation and failure behavior of non-stochastic porous structures processed by selective laser melting. Mater. Sci. Eng. A 2011, 528, 7962-7967.

28. Lhuissier, P.; Formanoir, C.; Martin, G.; Dendievel, R.; Godet, S. Geometrical control of lattice structures produced by EBM through chemical etching: Investigations at the scale of individual struts. Mater. Des. 2016, 110, 485-493.

29. Brenne, F.; Niendorf, T.; Maier, H.J. Additively manufactured cellular structures: Impact of microstructure and local strains on the monotonic and cyclic behavior under uniaxial and bending load. J. Mater. Process. Technol. 2013, 213, 1558-1564.

30. Suard, M.; Martin, G.; Lhuissier, P.; Dendievel, R.; Vignat, F.; Blandin, J.-J.; Villeneuve, F. Mechanical equivalent diameter of single struts for the stiffness prediction of lattice structures produced by Electron Beam Melting. Addit. Manuf. 2015, 8, 124-131.

31. Smith, M.; Guan, Z.; Cantwell, W.J. Finite element modelling of the compressive response of lattice structures manufactured using the selective laser melting technique. Int. J. Mech. Sci. 2013, 67, 28-41.

32. Yan, C.; Hao, L.; Hussein, A.; Young, P.; Raymont, D. Advanced lightweight 316L stainless steel cellular lattice structures fabricated via selective laser melting. Mater. Des. J. 2014, 55, 533-541.

33. Yan, C.; Hao, L.; Hussein, A.; Raymont, D. Evaluations of cellular lattice structures manufactured using selective laser melting. Int. J. Mach. Tools Manuf. 2012, 62, 32-38.

34. Alsalla, H.; Hao, L.; Smith, C. Fracture toughness and tensile strength of $316 \mathrm{~L}$ stainless steel cellular lattice structures manufactured using the selective laser melting technique. Mater. Sci. Eng. A 2016, 669, 1-6.

35. Gumruk, R.; Mines, R.A.W. Compressive behaviour of stainless steel micro-lattice structures. Int. J. Mech. Sci. 2013, 68, 125-139.

36. Gümrük, R.; Mines, R.A.W.; Karadeniz, S. Static mechanical behaviours of stainless steel micro-lattice structures under different loading conditions. Mater. Sci. Eng. A 2013, 586, 392-406.

37. McKown, S.; Shen, Y.; Brookes, W.K.; Sutcliffe, C.J.; Cantwell, W.J.; Langdon, G.S.; Nurick, G.N.; Theobald, M.D. The quasi-static and blast loading response of lattice structures. Int. J. Impact Eng. 2008, 35, 795-810.

38. Maskery, I.; Aboulkhair, N.T.; Aremu, A.O.; Tuck, C.J.; Ashcroft, I.A.; Wildman, R.D.; Hague, R.J.M. A mechanical property evaluation of graded density Al-Si10-Mg lattice structures manufactured by selective laser melting. Mater. Sci. Eng. A 2016, 670, 264-274.

39. Qiu, C.; Yue, S.; Adkins, N.J.E.; Ward, M.; Hassanin, H.; Lee, P.D.; Withers, P.J.; Attallah, M.M. Influence of processing conditions on strut structure and compressive properties of cellular lattice structures fabricated by selective laser melting. Mater. Sci. Eng. A 2015, 628, 188-197.

40. Leary, M.; Mazur, M.; Elambasseril, J.; McMillan, M.; Chirent, T.; Sun, Y.; Qian, M.; Easton, M.; Brandt, M. Selective laser melting (SLM) of AlSi12Mg lattice structures. Mater. Des. 2016, 98, 344-357.

41. Vacca, A. P.180 Main Wing Anti-Ice System: Analysis and Improvements. Master's Thesis, University of Genoa, Genova, Italy, 2013.

(C) 2017 by the authors. Licensee MDPI, Basel, Switzerland. This article is an open access article distributed under the terms and conditions of the Creative Commons Attribution (CC BY) license (http:/ / creativecommons.org/licenses/by/4.0/). 